\title{
Cost and losses associated with offshore wind farm collection networks which centralise the turbine power electronic converters
}

\author{
Max Alexander Parker, Olimpo Anaya-Lara \\ Department of Electrical and Electronic Engineering, University of Strathclyde, Royal College Building, 204 George Street, \\ Glasgow G1 1XW, UK \\ E-mail:max.parker@eee.strath.ac.uk
}

\begin{abstract}
Costs and losses have been calculated for several different network topologies, which centralise the turbine power electronic converters, in order to improve access for maintenance. These are divided into star topologies, where each turbine is connected individually to its own converter on a platform housing many converters, and cluster topologies, where multiple turbines are connected through a single large converter. Both AC and DC topologies were considered, along with standard string topologies for comparison. Star and cluster topologies were both found to have higher costs and losses than the string topology. In the case of the star topology, this is due to the longer cable length and higher component count. In the case of the cluster topology, this is due to the reduced energy capture from controlling turbine speeds in clusters rather than individually. DC topologies were generally found to have a lower cost and loss than AC, but the fact that the converters are not commercially available makes this advantage less certain.
\end{abstract}

\section{Introduction}

The power electronic converter on a variable-speed wind turbine, necessary to allow the speed to vary with a fixed grid frequency, is a significant source of turbine failure, and is also an expensive component of the turbine [1]. When the turbine is sited onshore, the converter can be repaired or replaced quickly compared with other components which require specialist lifting equipment, so converter reliability has previously been ignored. When the turbine is sited offshore, access is more limited and may not be possible at certain times of the year when the sea conditions are rough, making the achievement of a high converter reliability more important [2].

For larger turbines designed for offshore use, the doubly fed induction generator and partially-rated converter traditionally used in variable-speed turbines are being replaced by permanent-magnet or squirrel-cage induction generators, with fully-rated converters. This gives greater controllability during faults and decreased generator maintenance requirements, and an improved efficiency if a permanent-magnet generator is used. However, the use of a fully-rated converter increases the converter cost, and could increase the converter failure rate.

Fault-tolerant converters are currently being developed by turbine manufacturers as a way to increase the availability of the turbine in the event of a power electronics failure [3], and for conventional $690 \mathrm{~V}$ converters is fairly simple to achieve as these converters are normally composed of several modules in parallel. The increasing turbine size is leading to the increased use of medium-voltage converters, based on the integrated gate-commutated thyristor, which are not based on multiple identical modules, meaning that fault-tolerance will be more expensive to achieve [4]. Fault-tolerant medium-voltage multilevel converters based on low-voltage switching devices have been proposed, but these are complex and require multiple isolated voltage sources [5].

Another potential method to increase availability is to place the turbine converters together on their own platform, which could potentially be the main transmission platform, and this is the method considered in this paper. This would allow easier access for repairs, especially if the platform is permanently manned, and could feature spare converters which could be automatically switched in if the turbine converter fails. Two methods are evaluated: a star topology, where each turbine is connected to the platform individually, to its own converter, and a cluster topology, where multiple turbines are connected to a single large converter.

Many offshore wind farms, including most of the UK round three sites, will be located a significant distance from the shore, greater than the transmission distance possible with conventional AC cables. This will require the use of high-voltage direct current (HVDC) transmission, which will decouple the wind farm collection network from the national electricity grid, allowing a much greater flexibility in the design of the collection network. DC collection networks have been proposed by various groups $[6,7]$, with the main benefit being a reduction in the number of power 
electronic conversion steps, leading to a higher efficiency and lower equipment cost and weight. Both $\mathrm{AC}$ and DC versions of the star and cluster network topologies will be considered, and compared with the conventional string network. Power losses associated with the networks will be evaluated, along with costs associated with the collection network.

\section{Methodology}

A number of steps were carried out in this study:

- Select representative wind farm site and turbine size.

- Formulate a number of different network designs, including selecting voltage levels and the number of turbines per string.

- Design the physical layout of the wind farm, and cable routing, in order to calculate the cable lengths.

- Calculate the losses in the different components of the collection network at a number of wind speeds across the wind speed range of the turbine, based on a representative turbine power curve. Using the wind speed distribution for the site, calculate the total annual energy loss.

- Calculate the costs for each component, including the cost of the lifetime energy loss.

The purpose of this study is to produce a general comparison between different wind farm configurations, for a large wind farm on the scale of the UK Round three sites, and situated a significant distance from the shore. Time constraints and the lack of commercially available DC collection network cables, and hence DC cable data, mean that the collection cable voltage, cable size and the number of turbines per string have not been optimised to obtain the lowest cost of energy. Instead, the number of turbines per string is chosen to be the highest possible for the thermal rating of the largest available three-core wet-insulation $\mathrm{AC}$ cable, this giving the shortest cable length, with the same layout used for the DC string network and cluster networks. Ratings for other components such as transformers and power electronics are based on the rated power of these components, usually based on thermal limits.

\section{Network designs}

Star and cluster network topologies will be considered, and compared with conventional parallel string networks. More exotic network designs exist, involving series connection of turbines to eliminate the transmission platform [7, 8], but the technological challenges are significant and cable failure will result in the loss of a significant number of turbines; so these designs will not be considered here.

\subsection{Wind farm and turbine parameters}

Calculations are loosely based on the proposed Dogger Bank offshore wind farm. This is located between 125 and $290 \mathrm{~km}$ from the shore, requiring HVDC transmission and the estimated capacity for the site is $9 \mathrm{GW}$. The maximum capacity of a voltage-source HVDC link at $\pm 300 \mathrm{kV}$ is $1-1.2 \mathrm{GW}$, so the wind farm is to be built in stages in units of this size [9]. For this study, a capacity of $1 \mathrm{GW}$ is used.

For the turbine, a rating of $10 \mathrm{MW}$ was used, based on the trend towards larger turbines in offshore applications, and the limited capacity of three-core wet-insulation AC cables resulting in shorter string lengths, making star networks more attractive. Although $10 \mathrm{MW}$ turbines are not currently available, there are several large designs in development, as shown in Table 1. For the $10 \mathrm{MW}$ turbine used, the blade length of the RePower $5 \mathrm{M}$ was scaled by $\sqrt{2}$ in order to double the swept area. To maintain the same tip speed ratio, the rated speed of the turbine was divided by the same factor.

A high-speed generator is used, with six poles and a rated speed of $900 \mathrm{rpm}$, using a multi-stage step-up gearbox with a ratio of 1:120. All designs use a permanent-magnet generator with the exception of the AC cluster, which uses a squirrel-cage induction generator, as used in fixed-speed turbines. Increases in reliability and efficiency could be achieved using either a direct-drive generator or a medium speed generator with single stage gearboxes, although the cost benefit is uncertain [10], and induction generators of these designs are not available. The turbine parameters are shown in Table 2.

\subsection{Network diagrams}

String and cluster networks are shown in Figs. 1 and 2. All networks use non-tapered cable ratings, with adjacent strings connected at the ends using normally open links to allow some tolerance to cable faults [11]. The turbines in the string networks are connected in strings to the fixed frequency and voltage $\mathrm{AC}$ and fixed voltage $\mathrm{DC}$ buses using their own power electronic converter, to allow variable-speed operation. The turbines in the cluster networks are connected to variable frequency and voltage $\mathrm{AC}$ and variable voltage $\mathrm{DC}$ strings directly, or through a passive rectifier in the DC case. A single converter for each string is used to control the string frequency and voltage, which determines the turbine speed, meaning that all turbines operate at the same speed, although a small speed variation between turbines is possible. In both $\mathrm{AC}$ and $\mathrm{DC}$ cluster networks, the outputs of the string converters are collected in a DC bus. The AC cluster network has been covered in literature [12-14], and the proposed DC version has similar characteristics but could allow lower losses because of the permanent-magnet generator and easier turbine control [13]. The rectifier in the DC cluster network

Table 1 Current and future large turbine designs

\begin{tabular}{lccl}
\hline Turbine & $\begin{array}{c}\text { Rated } \\
\text { power, MW }\end{array}$ & $\begin{array}{c}\text { Blade } \\
\text { span, } \mathrm{m}\end{array}$ & \multicolumn{1}{c}{ Availability } \\
\hline Multibrid M5000 & 5 & 116 & available \\
RePower 5 M & 5 & 126 & available \\
RePower 6 M & 6 & 126 & available \\
Siemens SWT-6.0 & 6 & 154 & prototyping \\
Alstom Haliade 150 & 6 & 150 & prototyping \\
Vestas V164 & 7 & 164 & in development \\
WindTec Sea Titan & 10 & 190 & in development \\
\hline
\end{tabular}

Table 2 Turbine design used in this study

\begin{tabular}{lc}
\hline blade span & $170 \mathrm{~m}$ \\
rated wind speed & $12 \mathrm{~m} / \mathrm{s}$ \\
rated mechanical power & $10 \mathrm{MW}$ \\
rated turbine speed & $8.5 \mathrm{rpm}$ \\
gearbox ratio & $1: 120$ \\
cut-in wind speed & $3 \mathrm{~m} / \mathrm{s}$ \\
cut-out wind speed & $25 \mathrm{~m} / \mathrm{s}$ \\
\hline
\end{tabular}




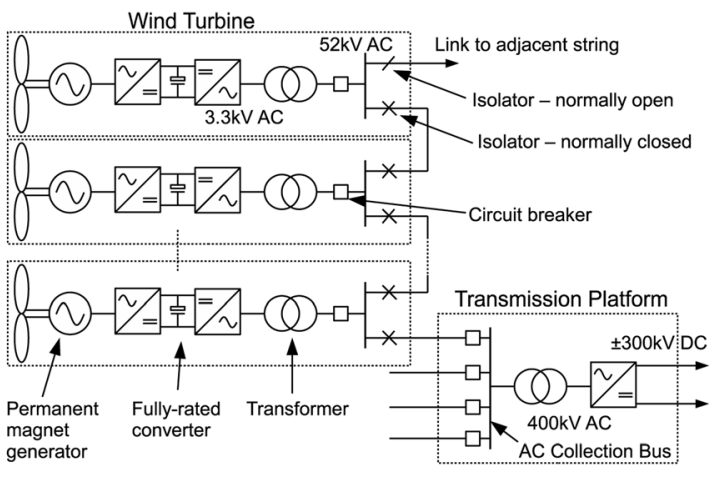

Fig. 1 Conventional parallel string connection of turbines

a $\mathrm{AC}$ connection

$b$ DC connection

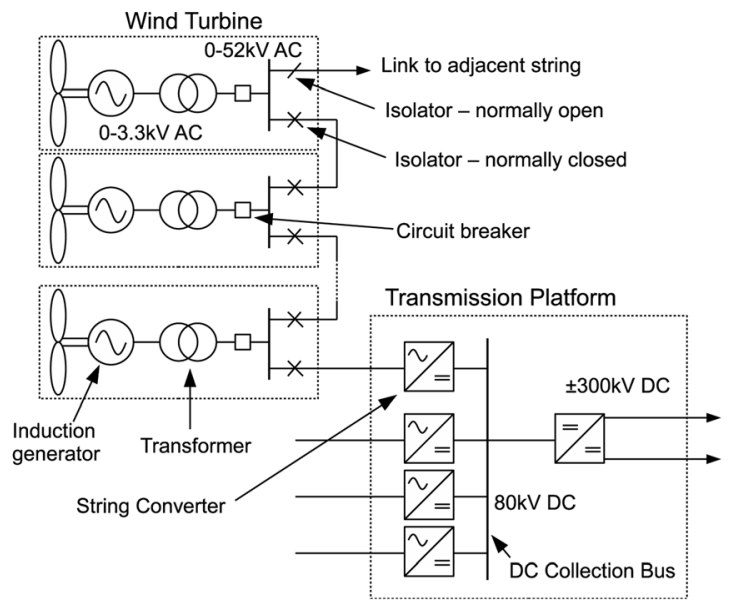

a

Fig. 2 Parallel cluster connection of turbines

a AC connection

$b$ DC connection

is a passive rectifier, and is considered to be reliable enough to not require frequent maintenance access.

For the AC networks, a $52 \mathrm{kV}$ AC string voltage was chosen rather than the more usual $33 \mathrm{kV}$ as it allows a greater number of turbines per string, and is the maximum rated voltage for wet-insulation cross-linked polyethylene (XLPE)-insulated cables from ABB [15]. For the DC networks, a $70 \mathrm{kV}$ string voltage was chosen as this has the same insulation requirements as the $52 \mathrm{kV}$ AC cable. In reality, there are no two-core XLPE cables on the market designed for this application. DC has the capability for higher cable capacity and longer strings than $\mathrm{AC}$ as the cables are not affected by the water treeing degradation issue which requires dry-insulation cables for higher voltages or skin depth, which limits utilisation of the conductor area with larger cables [16], but this capability is not used.

The star networks are shown in Fig. 3, where each turbine is connected individually to its own converter, which is located on one or more platforms. The converters in the AC and DC star networks are connected to fixed frequency and voltage $\mathrm{AC}$ and fixed voltage $\mathrm{DC}$ buses on each platform.

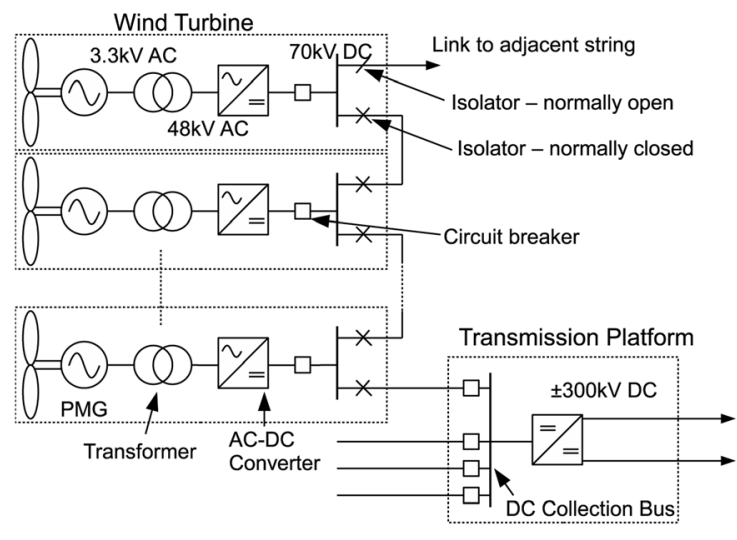

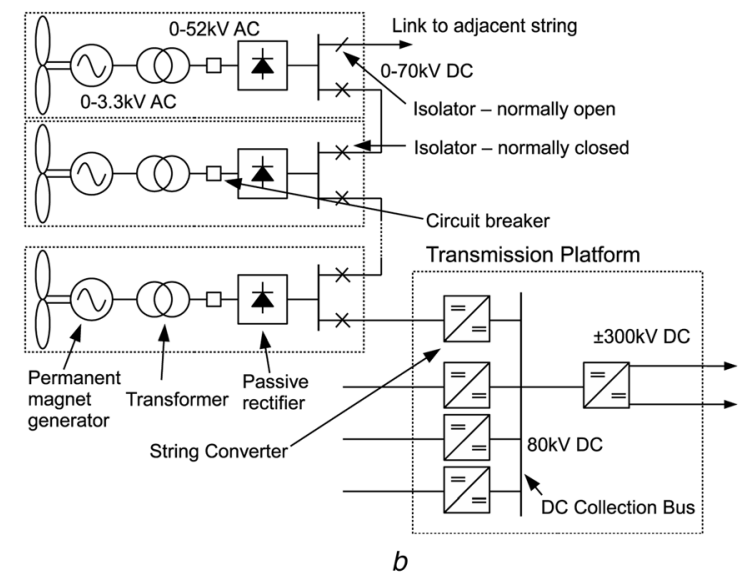

b
The AC and DC star networks use a generator with an 11 $\mathrm{kV}$ voltage in order to eliminate the turbine transformer; this is the highest voltage generally available in a high-speed generator of the required power rating. The generator is connected to the blade hub through a step-up gearbox, which is not shown in the diagram. The collection platforms are connected to the transmission platform via a loop network at $220 \mathrm{kV}$ AC or $\pm 150 \mathrm{kV} \mathrm{DC}$, which allows some tolerance of cable faults. $220 \mathrm{kV}$ AC was the highest AC cable voltage for which cost data were available, higher voltages generally not being used offshore because of the high capacitance limiting the current capability. $\pm 150 \mathrm{kV}$ cable from $\mathrm{ABB}$ is the lowest voltage rating to provide the required $500 \mathrm{MW}$ capacity.

The AC star network was designed to use standard components and techniques, which leads to a more reliable cost estimate but a higher cost and complexity. The hybrid star network was created in order to reduce some of the costs and losses associated with the AC and DC star networks. AC collection, with a higher cable voltage and turbine transformer was used, to reduce cable costs and losses. A more exotic conversion system was used, based on high-voltage 

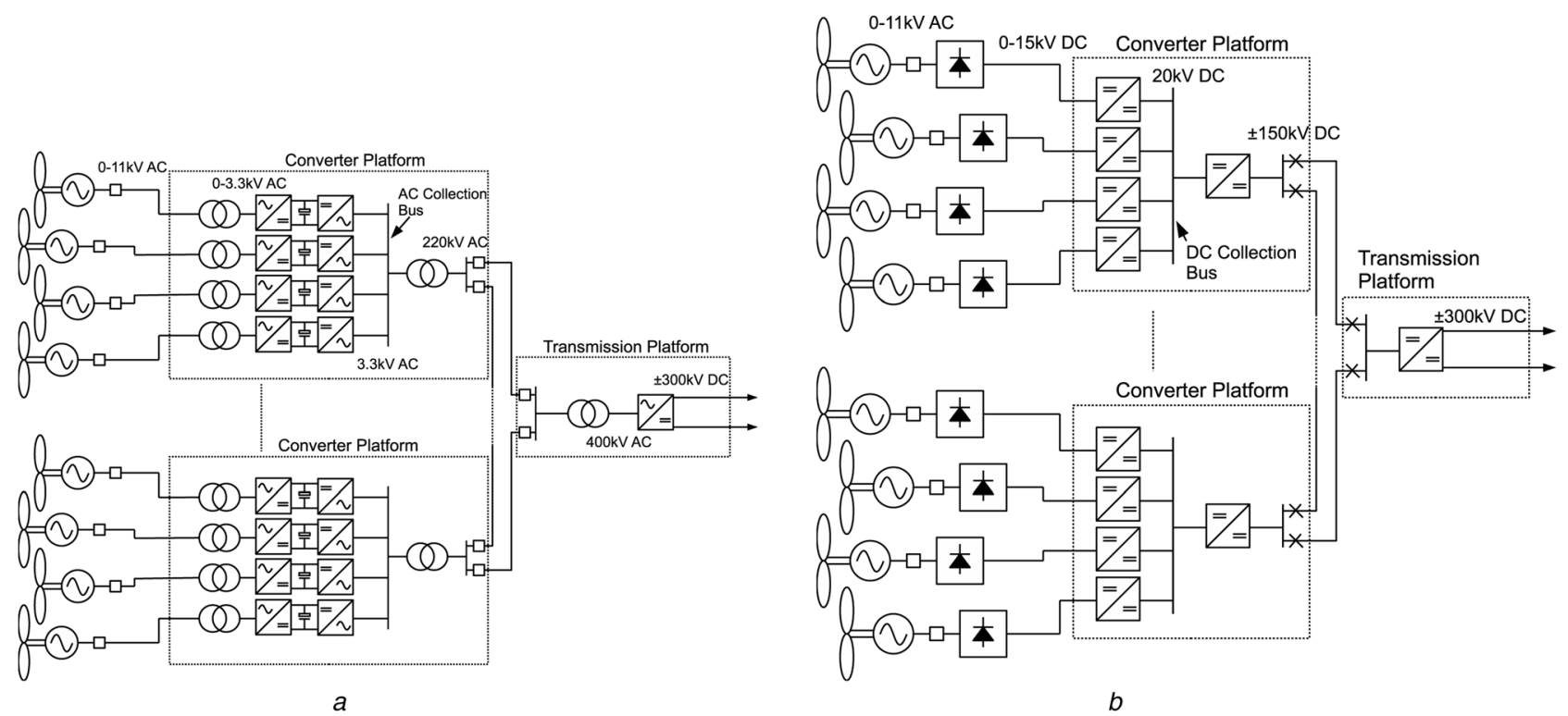

a

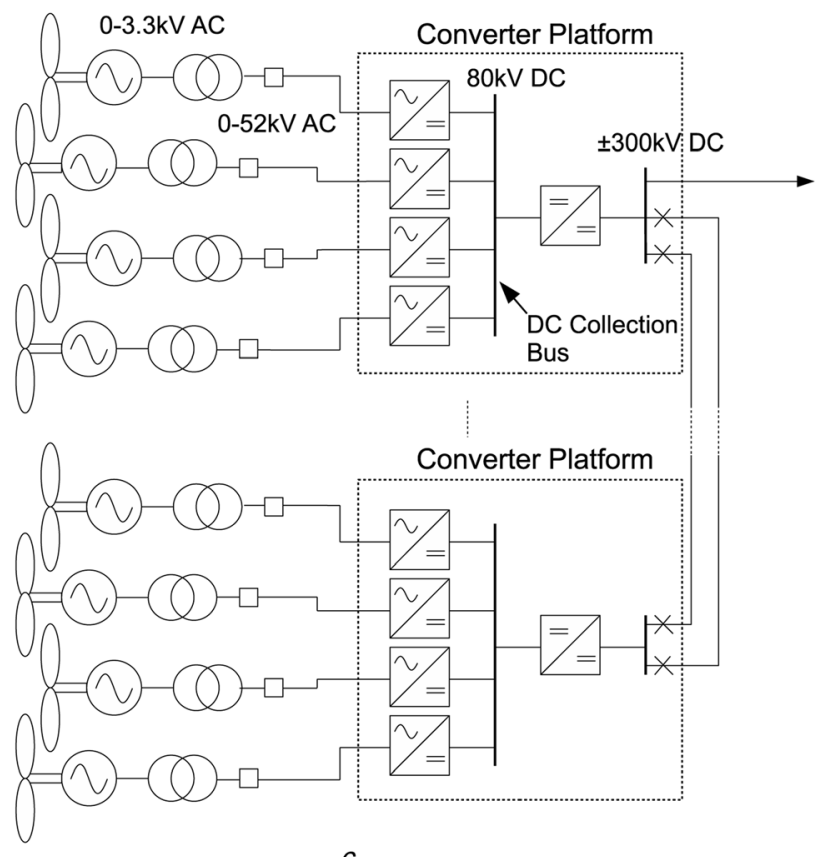

Fig. 3 Star connection of turbines

a AC connection

$b$ DC connection

$c$ Hybrid network

converters and DC collection buses, feeding onto a loop network at the transmission voltage in order to reduce the number of transformer and converter steps.

\subsection{Converter configuration}

Table 3 shows the converters used in the different network designs, with converters that are commercially available in the required voltage and power rating shown in bold type. The rectifier column shows whether the turbine contains a passive rectifier. NPC refers to a three-level neutral-pointclamped AC-DC-AC converter, with a $3.3 \mathrm{kV}$ voltage rating. Such converters are used in some larger turbines, and are likely to become more common as turbine sizes increase [4]. MMC refers to a modular multilevel AC-DC converter, which is usually used for voltage-source HVDC
Table 3 Converters used for the network designs

\begin{tabular}{|c|c|c|c|c|}
\hline & \multirow[b]{2}{*}{ Rectifier } & \multirow[b]{2}{*}{ Turbine } & \multicolumn{2}{|c|}{ Converter type } \\
\hline & & & Collection & Transmission \\
\hline AC string & $\mathrm{N}$ & NPC & $\mathrm{n} / \mathrm{a}$ & MMC \\
\hline DC string & $\mathrm{N}$ & MMC & $\mathrm{n} / \mathrm{a}$ & fullbridge \\
\hline AC cluster & $\mathrm{N}$ & $\mathrm{n} / \mathrm{a}$ & MMC & fullbridge \\
\hline DC cluster & $Y$ & $\mathrm{n} / \mathrm{a}$ & boost & fullbridge \\
\hline AC star & $\mathrm{N}$ & NPC & $\mathrm{n} / \mathrm{a}$ & MMC \\
\hline DC star & $Y$ & boost & fullbridge & boost \\
\hline hybrid star & $\mathrm{N}$ & MMC & fullbridge & $\mathrm{n} / \mathrm{a}$ \\
\hline
\end{tabular}

transmission [17], and unlikely to be available at ratings below several tens of MW. Boost refers to a boost-type DC-DC converter, whereas Fullbridge refers to a 
transformer isolated fullbridge converter, neither of which are available at the required voltage and power rating.

\section{Farm physical layout}

All layouts are based on a wind farm consisting of a rectangular grid of $10 \times 10$ turbines, spaced with a distance of seven turbine diameters in both the crosswind and downwind directions.

\subsection{String and cluster networks}

The string and cluster networks have an identical layout. A more detailed consideration of the cluster network would take account of variations in the wind direction and the resulting wake effects on the power capture, and would optimise the layout to minimise these effects [14]. However, this would require a much more detailed analysis, including site-specific conditions which are not known.

For the these networks, the transmission platform is placed outside the farm area for ease of access. Connections between the ends of strings and the transmission platform are made using the shortest distance possible, although the real distance would be likely to be longer in order for the cables not to cross. The layout is shown in Fig. 4 and a breakdown of the cable lengths for the different cables is given in Table 4.

\subsection{Star networks}

For the star layout, four collector platforms has been found to be optimal in terms of cost [18]. A larger number of platforms will reduce the length of the collection cable, but increase the length of the loop network cables between platforms, which have a much greater cost per $\mathrm{km}$. A larger number of platforms would also be less convenient for maintenance, as more platforms would need to be visited. Locating the collector platforms outside the wind farm leads to excessive cable lengths, making the design non-viable; so the collector platforms are located within the wind farm. The

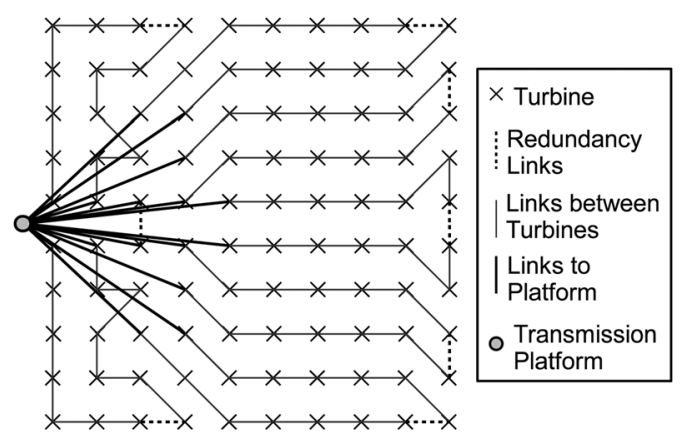

Fig. 4 Wind farm layout for string and cluster connection

Table 4 Cable lengths for a string and cluster connection

\begin{tabular}{lc}
\hline turbines per string & 7 \\
number of strings & 14 \\
inter-turbine links & $117 \mathrm{~km}$ \\
redundancy links & $5 \mathrm{~km}$ \\
strings to platform & $52 \mathrm{~km}$ \\
total cable length & $174 \mathrm{~km}$ \\
\hline
\end{tabular}

layout is shown in Fig. 5, and the cable lengths are given in Table 5.

\section{Loss and cost calculation methodology}

\subsection{Loss calculation}

Losses were calculated for different wind speeds between the cut-in and cut-out speeds shown in Table 2. It is assumed that below the rated wind speed of the turbine, the turbine speed will vary in proportion to the wind speed in order to track the maximum power operating point of the turbine. Above the rated wind speed, the turbine speed will be held constant at the rated speed, and the power will be held at the rated power using pitch control.

Turbine mechanical power for a wind speed $v_{\mathrm{w}}$ is calculated as follows

$$
P=0.5 C_{\mathrm{p}} A \rho v_{\mathrm{w}}^{3}
$$

where $P$ is the turbine power, $A$ the swept area, $\rho$ the density of air. $C_{\mathrm{p}}$ is the coefficient of performance, which depends on the tip speed ratio of the turbine, and is constant in this case as the turbine is assumed to be operating at the most efficient speed when the wind speed is below the rated wind speed. The turbine was sized to obtain a $10 \mathrm{MW}$ mechanical power at the rated wind speed, so the actual electrical power output will be lower. Subtracting the electrical losses from the mechanical power at each wind speed gives the power curve for the wind farm.

Annual energy capture was obtained by multiplying the output power at each wind speed by the number of hours per year that the wind will be at that speed. The wind speed is assumed to follow the Rayleigh distribution, the cumulative distribution function (CDF) for which is given in (2), where $v_{\mathrm{W}}$ is the wind speed and $\overline{v_{\mathrm{W}}}$ is the average wind speed for the area. An average wind speed of $9.83 \mathrm{~m} / \mathrm{s}$ is used, as this is the average wind speed for the Dogger Bank site.

$$
P\left(v \leq v_{\mathrm{w}}\right)=1-\mathrm{e}^{(-\pi / 4)\left(v_{\mathrm{w}}^{2} / 4{\overline{v_{\mathrm{w}}}}^{2}\right)}
$$

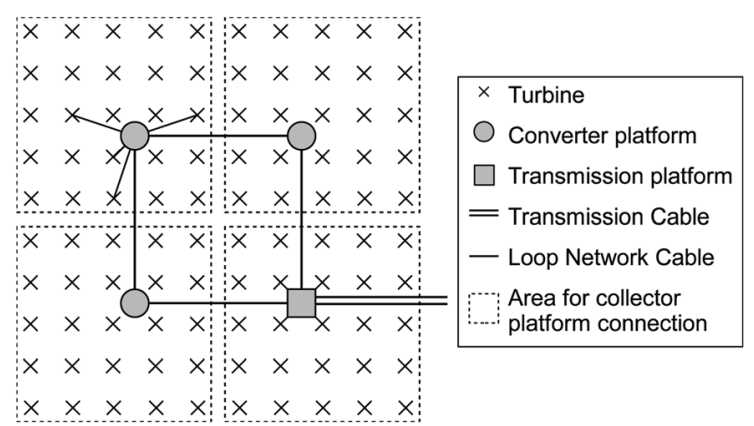

Fig. 5 Wind farm layouts for star connection, with four collector platforms

Table 5 Cable lengths for a star connection

\begin{tabular}{lc}
\hline number of collector stations & 4 \\
connections to turbines & $223 \mathrm{~km}$ \\
loop network & $24 \mathrm{~km}$ \\
total cable length & $247 \mathrm{~km}$ \\
\hline
\end{tabular}


Matlab scripts were used to calculate the losses of the components at each wind speed, with each loss being used to calculate the power input to the next component. For the AC connection arrangements, some calculations were repeated once the reactive power requirements of the downstream components were found. For the cluster topologies, the annual reduction in energy capture because of the loss of individual speed control of the turbines has been estimated to be around $1.5 \%$ for a $9 \mathrm{~m} / \mathrm{s}$ average wind speed [13], and this percentage of the total energy capture is used for the clustering loss.

5.1.1 Generator, transformer and cable: Losses for the generator, transformers and cables were calculated from the equivalent circuit parameters, which are given in Table 6 for the generators. Several networks use transformers and/or cables, which operate at a variable AC frequency and voltage. In this case, the frequency is assumed to be proportional to the turbine speed, which is varied in proportion to the wind speed up to the rated wind speed, and held constant thereafter. In the case of the induction generator in the $\mathrm{AC}$ cluster network the effects of generator slip are ignored.

The induction generator parameters were obtained from the UpWind project [19]. The UpWind PM generator design used a high pole number, giving a high frequency and a high reactance, which are fine for direct connection through a converter, but not suitable where transformers and cables designed for a $50 \mathrm{~Hz} \mathrm{AC}$ frequency, or passive rectifiers, are used. For the purposes of this study, a permanent-magnet rotor was designed for the UpWind induction generator stator, with the magnet height and airgap size set to achieve the same flux density as the induction generator, and a per-unit reactance of 0.4 .

The induction generator flux was optimised for each wind speed to obtain the lowest generator and cable losses. Where a passive rectifier was not used, the PM generator terminal voltage was set to equal the generated EMF. Where the generator connects through a passive rectifier, it is assumed that the voltage and current will be sinusoidal, and the terminal voltage in phase with the current, which is reasonably valid with the leakage reactances used.

The transformer equivalent circuit parameters are given in Table 7, and are based on typical values from large oil-filled

Table 6 Generator equivalent circuit parameters

\begin{tabular}{lcc}
\hline Parameter & \multicolumn{2}{c}{ Per-unit value } \\
\cline { 2 - 3 } & Induction & $\mathrm{PM}$ \\
\hline number of poles & 6 & 6 \\
rotor resistance $\left(R_{\mathrm{r}}^{\prime}\right)$ & 0.002 & $\mathrm{n} / \mathrm{a}$ \\
stator resistance $\left(R_{\mathrm{s}}\right)$ & 0.0063 & 0.0063 \\
rotor leakage reactance $\left(X_{\mathrm{Ir}}^{\prime}\right)$ & 0.0592 & $\mathrm{n} / \mathrm{a}$ \\
stator leakage reactance $\left(X_{\mathrm{Is}}\right)$ & 0.0624 & 0.4031 \\
magnetising reactance $\left(X_{\mathrm{m}}\right)$ & 6.0509 & $\mathrm{n} / \mathrm{a}$ \\
\hline
\end{tabular}

Table 7 Transformer equivalent circuit parameters

\begin{tabular}{lc}
\hline Parameter & Per-unit value \\
\hline primary/secondary resistance $(R)$ & 0.003 \\
primary/secondary leakage reactance $\left(X_{\mathrm{l}}\right)$ & 0.045 \\
magnetising reactance $\left(X_{\mathrm{m}}\right)$ & 125 \\
iron loss resistance $\left(R_{\mathrm{m}}\right)$ & 300 \\
\hline
\end{tabular}

transformers [20]. The same parameters are used for all transformers in the study. Where the transformers operate with a variable $\mathrm{AC}$ frequency, the iron loss resistance was assumed to remain constant as the data on the transformer physical design necessary to calculate this value accurately was not known. Magnetising and leakage reactances were calculated for the different frequencies, and the variable frequency and voltage leads to lower charging currents at lower wind speeds, leading to lower losses in the transformer, cable and power electronics.

AC cables were modelled using a $\pi$-section equivalent circuit. The individual cable sections were considered to be sufficiently short that the long line equations were not required, and it was assumed that any reactive power requirements of the cable will be met equally by the terminals at each end when these terminals feature power electronic converters.

$\mathrm{AC}$ cable parameters were taken from a datasheet of $\mathrm{ABB}$ XLPE cables [15]. For the DC cables, there are no commercially available two-core collection network-type cables, so the cable parameters for the collection network cables were taken from those of the three-core AC cables, but with one fewer core. The DC loop network cable parameters were taken from a datasheet of ABB HVDC light cables [21]. The cable parameters are shown in Table 8.

AC cable resistance was calculated from the conductor area, and modified by the skin depth at the AC frequency and conductor diameter according to [7]. Where the AC frequency in the cable varies with wind speed, lower wind speeds will result in a lower $\mathrm{AC}$ resistance and lower losses, as well as a lower charging current, which leads to a further reduction in losses in the cables, transformers and power electronics. For DC cables the only parameter of interest is the DC resistance, as the analysis is steady state, and this is found from the conductor area.

5.1.2 Power electronics: Four types of converter are used in this study, broken down to two each of AC-DC and DCDC. For AC-DC or DC-AC conversion, the three-level neutral-point-clamped (NPC) converter is used for use up to $3.3 \mathrm{kV}$ AC voltage, and the modular multilevel converter (MMC) used for higher voltages. For DC-DC conversion, the boost converter is used for small increases in voltage and the isolated fullbridge converter, featuring a step-up transformer, is used where a large increase in voltage is required.

The AC-DC converters are shown in Fig. 6. For both converters, the instantaneous $\mathrm{AC}$ current and voltage were calculated at equal time steps across the $\mathrm{AC}$ waveform, which depend on the real and reactive power flow. The power losses at each of these points were calculated, and used to find the average power loss. The NPC converter synthesises the AC voltage by switching rapidly between two different configurations, with the configurations depending on the current and voltage directions, and the average voltage determined by the duty cycle of the switching and the DC-link voltage. The conduction losses in each configuration can be calculated, and the overall power loss calculated by multiplying the calculated losses by the instantaneous duty cycle - the proportion of time spent in that configuration. Switching losses were calculated assuming the switching events occur at a fixed frequency.

The MMC uses a large number of modules which can be switched to either $0 \mathrm{~V}$ or the capacitor voltage, and the AC voltage is synthesised by switching different numbers of modules in the top and bottom legs. For each time step, the 
Table 8 Cable parameters $[15,21]$

\begin{tabular}{|c|c|c|c|c|c|c|}
\hline & $\begin{array}{l}\text { AC/DC string/ } \\
\text { cluster }\end{array}$ & $\begin{array}{l}\text { AC/DC star, turbine } \\
\text { to platform }\end{array}$ & $\begin{array}{c}\text { AC star, loop } \\
\text { network }\end{array}$ & $\begin{array}{l}\text { DC star, loop } \\
\text { network }\end{array}$ & $\begin{array}{l}\text { Hyb. star to } \\
\text { platform }\end{array}$ & $\begin{array}{c}\text { Hyb. star loop } \\
\text { network }\end{array}$ \\
\hline $\begin{array}{l}\text { rated voltage (to } \\
\text { ground), kV }\end{array}$ & 30 & 10 & 220 & 160 & 30 & 300 \\
\hline cable cores & $3 / 2$ & $3 / 2$ & 1 & 1 & 3 & 1 \\
\hline conductor area, $\mathrm{mm}^{2}$ & 800 & 300 & 1400 & 1400 & 70 & 630 \\
\hline $\begin{array}{l}\text { conductor diameter, } \\
\mathrm{mm}\end{array}$ & 33.7 & 20.4 & 44.4 & - & 9.6 & - \\
\hline inductance & $310 \mu \mathrm{H} / \mathrm{km}$ & $320 \mu \mathrm{H} / \mathrm{km}$ & $1.32 \mathrm{mH} / \mathrm{km}$ & - & $460 \mu \mathrm{H} / \mathrm{km}$ & - \\
\hline capacitance, $\mu \mathrm{F} / \mathrm{km}$ & 0.38 & 0.53 & 0.21 & - & 0.16 & - \\
\hline
\end{tabular}
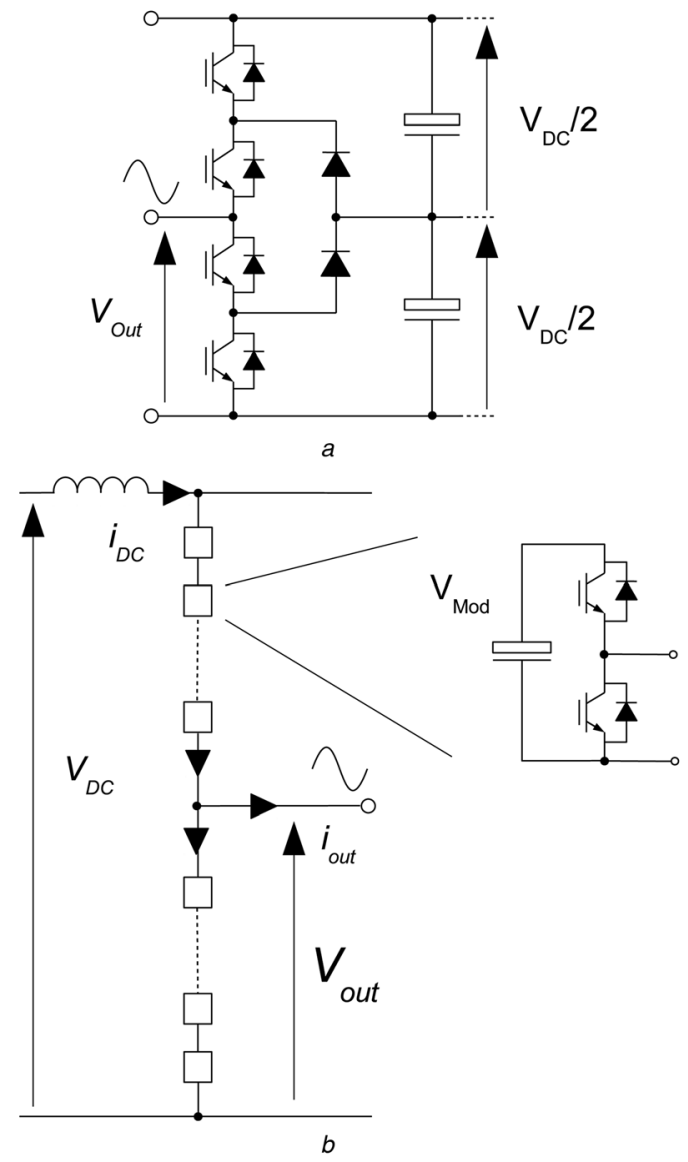

Fig. 6 One leg of AC-DC converters, including

$a$ Neutral-point-clamped

$b$ Modular multilevel

required output voltage was calculated, and the number of modules in each switching state was determined. The switching states of the modules were used to calculate the conduction losses based on the number of diodes and transistors in the current path.

The DC-DC converters are shown in Fig. 7. For both converters, the duty cycle of the switching was calculated based on the input and output voltages and in the case of the fullbridge converter the turns ratio of the transformer. Conduction and switching losses were calculated for the on and off states as with the NPC converter. The transformer for the fullbridge converter was assumed to have the same parameters as the low-frequency transformers used in the rest of the study, and for simplicity the transformer current was assumed to be sinusoidal.

For all converters, the MBN900D45A insulated gate bipolar transistor (IGBT) from Hitachi was selected, which

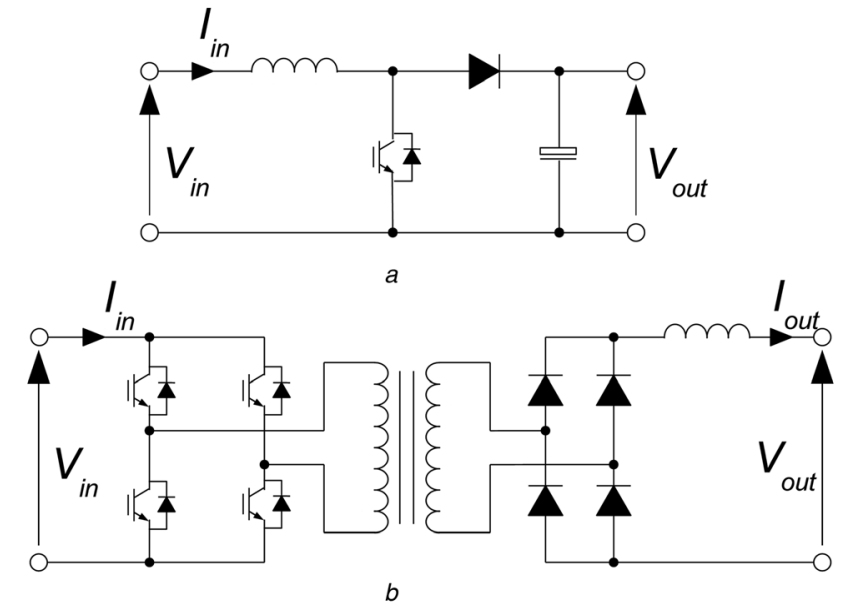

Fig. $7 \quad D C-D C$ converters, including

$a$ Boost converter

$b$ Isolated fullbridge converter

is rated at $4.5 \mathrm{kV}$ and $900 \mathrm{~A}$ continuous current, which has the required rating for the $10 \mathrm{MVA}$ NPC converter. The parameters used are given in Table 9. For the MMC, each module uses two IGBTs, and the number of modules in series is determined by the required voltage rating and the number of converters in parallel determined by the current rating. For the DC-DC converters the number of IGBTs in series and parallel is determined by the required voltage and current rating. Rectifier diodes were assumed to have the same parameters as the freewheeling diodes in the MBN900D45A. In the loss calculations, the switch and diode voltage drops were approximated by a constant voltage in series with a resistance, and the effects of device temperature were ignored.

\subsection{Cost calculation}

Initial capital costs and the lost earnings associated with the electrical losses are considered in this study, with the impact of the different collection network designs on the

Table 9 MBN900D45A IGBT parameters

rated collector-emitter voltage $4500 \mathrm{~V}$ rated DC current switch voltage drop $900 \mathrm{~A}$ switch resistance $2.6 \mathrm{~V}$ diode voltage drop diode resistance

turn-on loss per amp conducted turn-off loss per amp conducted
$1.61 \mathrm{~m} \Omega$

$2.6 \mathrm{~V}$

$0.97 \mathrm{~m} \Omega$

$2.44 \mathrm{~mJ} / \mathrm{A}$ $2.22 \mathrm{~mJ} / \mathrm{A}$ 
operations and maintenance costs being the subject of a separate project.

5.2.1 Cost of losses: Annual energy loss is multiplied by a representative market price for electricity of $£ 36 / \mathrm{MWh}$ for electricity and $£ 40 / \mathrm{MWh}$ for renewable obligation certificate (ROCs), obtained from another study [10], in order to determine the cost of the losses. These annual costs for the lifetime of the turbine were converted to a net present value (NPV) as follows

$$
\mathrm{NPV}=\frac{R}{i}\left(1-\frac{1}{(1+i)^{n}}\right)
$$

where $R$ is the annual revenue loss, $i$ is the discounting rate and $n$ the lifetime of the wind farm in years. A discounting rate of $10 \%$ was used, and a lifetime of 20 years.

5.2.2 Platforms, cables and transformers: Costs for these components were taken from another study, which obtained the parameters although curve fitting of commercially available components, and extrapolating where the components are not available in the required rating [7]. This study is almost 10 years old, so prices may be inaccurate, but a more recent source of data in a similarly useful form was not available. For this reason, the prices are multiplied by a factor of 1.28 , representing 10 years of inflation at $2.5 \%$ per annum. This is somewhat inaccurate, as it does not properly reflect changes in prices of materials and advances in manufacturing, but should be sufficient for comparison between the different network layouts.

The transmission platform cost, which does not include the cost of the platform equipment, is as follows

$$
\text { cost }=A+B P
$$

where $P$ is the rated power and $A$ and $B$ are constants, and are $£ 2400000$ and $£ 83800 / \mathrm{MW}$, respectively. In the referenced study, the constants are based on a large transmission platform containing accommodation and workshops, and these parameters are used in this study for the transmission platform. For the converter platforms in the star configuration, a simpler platform will be required so the parameters are halved. For the star configuration, one platform is designated a transmission platform, containing both collector and transmission equipment, whereas the remainder are collection platforms at half the cost. The hybrid star topology is still likely to have one larger platform for accommodation and workshops, even if it has no extra transmission equipment, so cost is the same as the other star topologies.

For all cables, an installation cost of $£ 288000 / \mathrm{km}$ was used. AC cable cost is given by (5), and DC cable cost by (6). $A, B$ and $C$ are constants, and $S$ and $P$ are the apparent and real powers carried by the cables. Values of the parameters are given in Table 10 for $\mathrm{AC}$ cables and Table 11 for DC cables.

$$
\begin{gathered}
\operatorname{cost}_{\mathrm{AC}}=A+B \mathrm{e}^{\left(C S / 10^{8}\right)} \\
\operatorname{cost}_{\mathrm{DC}}=A+B P
\end{gathered}
$$

Transformer cost is given by (7), where $S$ is the rated apparent power, and $A, B$ and $\beta$ are constants, with the values of $£ 145000, £ 240 / \mathrm{VA}$ and 0.4473 , respectively. The
Table 10 AC cable cost parameters

\begin{tabular}{lccc}
\hline Parameter & $\begin{array}{c}\text { String/cluster/Opt. } \\
\text { star to platform }\end{array}$ & $\begin{array}{c}\text { Star, turbine to } \\
\text { platform }\end{array}$ & $\begin{array}{c}\text { Star, loop } \\
\text { network }\end{array}$ \\
\hline voltage, & 52 & 11 & 220 \\
$\mathrm{kV}$ & & & \\
$A(/ \mathrm{km})$ & $£ 49300$ & $£ 34000$ & $£ 381000$ \\
$B(/ \mathrm{km})$ & $£ 71400$ & $£ 69900$ & $£ 13200$ \\
$C(\mathrm{~W})$ & 4.10 & 6.15 & 1.16 \\
\hline
\end{tabular}

Table 11 DC cable cost parameters

\begin{tabular}{lcccc}
\hline Parameter & $\begin{array}{c}\text { String/ } \\
\text { cluster }\end{array}$ & $\begin{array}{c}\text { Star, turbine } \\
\text { to platform }\end{array}$ & $\begin{array}{c}\text { Star, loop } \\
\text { network }\end{array}$ & $\begin{array}{c}\text { Opt. Star, } \\
\text { loop } \\
\text { network }\end{array}$ \\
\hline voltage, kV & 70 & 15 & 150 & 300 \\
$A(/ \mathrm{km})$ & $£ 37600$ & $£ 37600$ & $£ 9500$ & $£ 202000$ \\
$B(/ \mathrm{kmMW})$ & $£ 7400$ & $£ 14800$ & $£ 1430$ & $£ 600$ \\
\hline
\end{tabular}

cost parameters were taken from transformers with ratings from 6.3 to $150 \mathrm{MVA}$, with high side voltages from 47 to $140 \mathrm{kV}$ and low side voltages from 10.5 to $77 \mathrm{kV}$. The transformers used to obtain the parameters are assumed to be oil-filled, so the cost estimate may not be valid for the resin-insulated transformers likely to be used on the turbines.

$$
\operatorname{cost}=A+B S^{\beta}
$$

5.2.3 Generators and power electronics: For the induction generator, the cost of a $10 \mathrm{MW}$ generator calculated in the UpWind project, of $£ 208000$ per generator, was used [19]. For the permanent-magnet generator, the cost of the rotor copper was subtracted from the UpWind induction generator, and the cost of the permanent magnets added to give a cost of $£ 223000$. A magnet cost of $€ 40 / \mathrm{kg}$ was used, as in the UpWind project. This cost may be significantly higher today, but the magnets only contribute towards around $15 \%$ of the generator cost so the difference in overall system cost will be minimal.

Costing of power electronics for the different network topologies is difficult as many of them use converters which are not available commercially in the sizes required. The source for most of the cost data used in this study uses a cost of $£ 120 / \mathrm{kVA}$ for all converters, irrespective of type or size [10], whereas other studies used a cost of $£ 34 / \mathrm{kVA}$ $[19,22]$. These are the cost for a back-to-back AC-DC-AC converter, and a cost of $£ 60 / \mathrm{kVA}$ will be used in this study for single AC-DC or DC-DC converters, with the sensitivity of the total cost to the power electronics cost also calculated. Passive rectifiers are assumed to be $20 \%$ of the cost of a full converter.

The converters with transformer isolation will also have the cost of a transformer added, which is calculated using the same parameters as for the low-frequency transformers. Although a high-frequency transformer is likely to be smaller, and therefore have a lower mass of raw materials, the higher frequency of operation will lead to a more complex construction, and the cost reduction is assumed to be minimal. 
One survey of drivetrain designs has shown power electronic costs reducing with converter size [23], which would favour the cluster designs, as they eliminate the smaller turbine converters. It is also the case that the DC-DC converters have a significantly higher switch utilisation than $\mathrm{AC}-\mathrm{DC}$, which could reduce the cost of these converters, favouring the topologies with a DC collection network, but these converters are not commercially available in the sizes required, so this is not certain.

\section{Evaluation}

\subsection{Losses}

A breakdown of the annual energy losses by component type for the different network topologies is shown in Fig. 8. Generator loss is broadly similar for all topologies, but the induction generator in the $\mathrm{AC}$ cluster has the highest loss, because of the addition of the rotor copper loss. The DC cluster and string topologies also have a higher loss, because of the connection of the generator via a passive rectifier. Cable losses are significantly higher for the AC and DC star topologies because of the longer cable lengths and lower voltage rating. The hybrid star topology uses a higher voltage, and the cable is under-utilised as the minimum cable size still has a capacity greater than that of the single turbine to which it is connected, and this leads to low cable losses. The AC and DC string and cluster topologies have low cable losses because of the higher voltage, but also because the decision not to taper the cable diameter towards the string ends means that the cable there is under-utilised.

Power electronics and transformer losses should be considered together, as they often perform a similar function in the different network topologies, and some of the converters also include transformers. The AC and DC star topologies both have a high loss for these components, because of the number of conversion steps. The AC star topology has a large number of transformers and relatively efficient power electronics, whereas the DC star topology has several converters switching at high frequency, leading to high switching losses, as well as a converter with integral transformer.

The DC string topology has one fewer conversion step than the $\mathrm{AC}$ equivalent, leading to a lower power electronic loss.

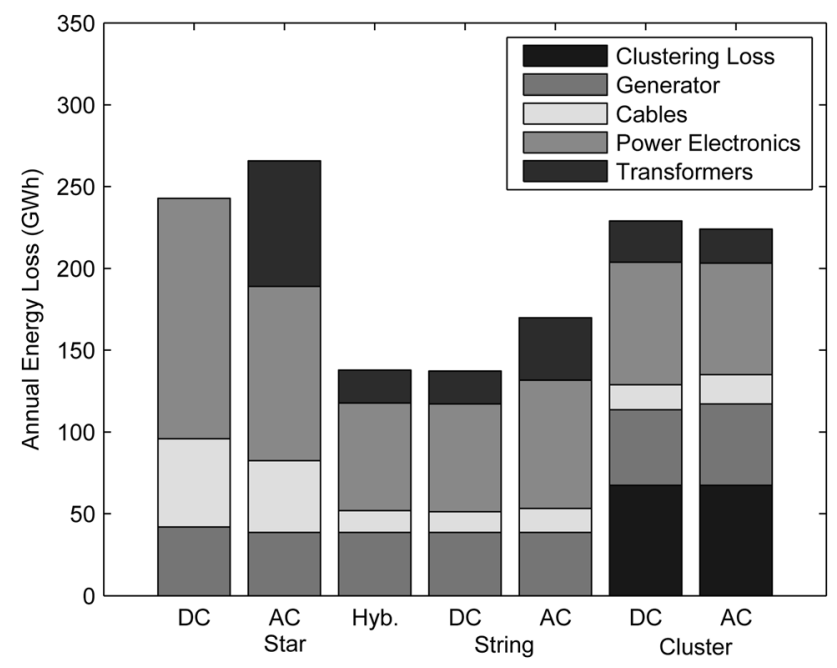

Fig. 8 Breakdown of annual losses by component type
The cluster topologies both have a similar power electronics and transformer loss, being of similar design, which is again similar to that of the DC string, all having the same number of conversion steps. The cluster topologies also suffer from the loss of energy capture because of clustering, which pushes the total losses above those of the string and DC star topologies. The hybrid star topology has broadly similar power electronic systems to the DC string, leading to similar losses.

\subsection{Costs}

A breakdown of the costs, including capital costs and costs of the annual losses, is shown in Fig. 9. Generally the DC topologies feature a slightly lower cable cost, whereas the star topologies have a higher cable cost because of the greater cable length, as well as a higher platform cost because of the larger number of platforms. Power electronics cost is generally lower in the DC topologies, because of the reduced number of conversion steps, but the reverse is true for the cluster networks, where the DC topology has an extra conversion step in the form of the passive rectifier in each turbine. The AC and DC star topologies have a higher power electronics cost because of the increased number of conversion steps, but the hybrid star topology has a similar cost to the DC string. Transformer and generator costs make a minimal difference. Overall, the AC and DC star topologies have a higher cost than the alternatives, with the cluster topologies being similar to the AC string topology, but more expensive than the DC string. The hybrid star topology is similar in cost to the DC string, but with higher cable and platform costs because of the longer cable lengths and extra platforms.

\subsection{Sensitivity to component costs}

Power electronics cost is a significant component of the total cost, and different studies have used a range of values for power electronics price, from $£ 17 / \mathrm{kVA}$ up to $£ 47 / \mathrm{kVA}$. The effect of varying the power electronics price on the total cost of the different topologies was calculated, and is shown in Fig. 10. AC star and DC string remain the most expensive and cheapest topologies with DC star not changing position. The cluster topologies, having a low

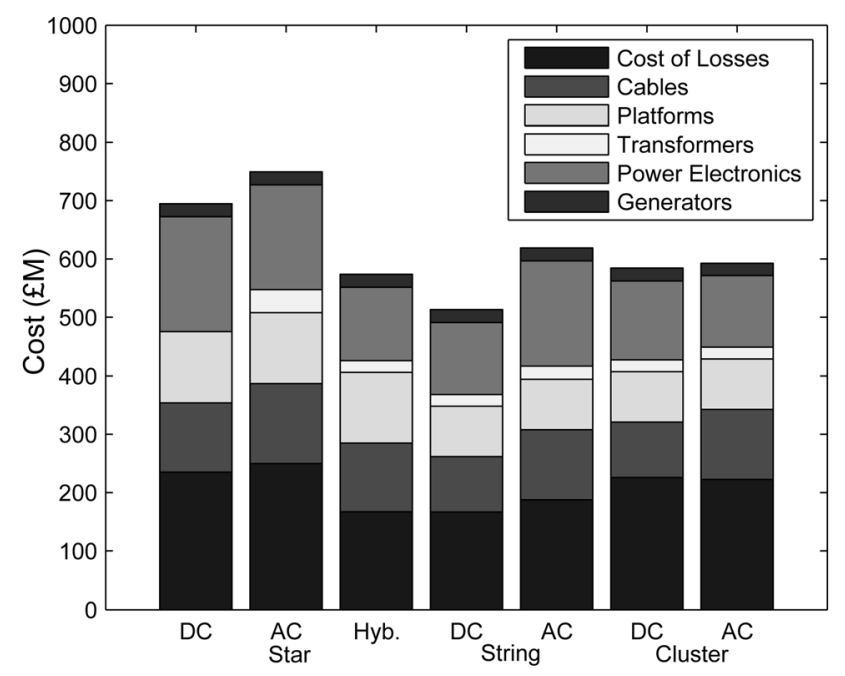

Fig. 9 Breakdown of cost by component type 


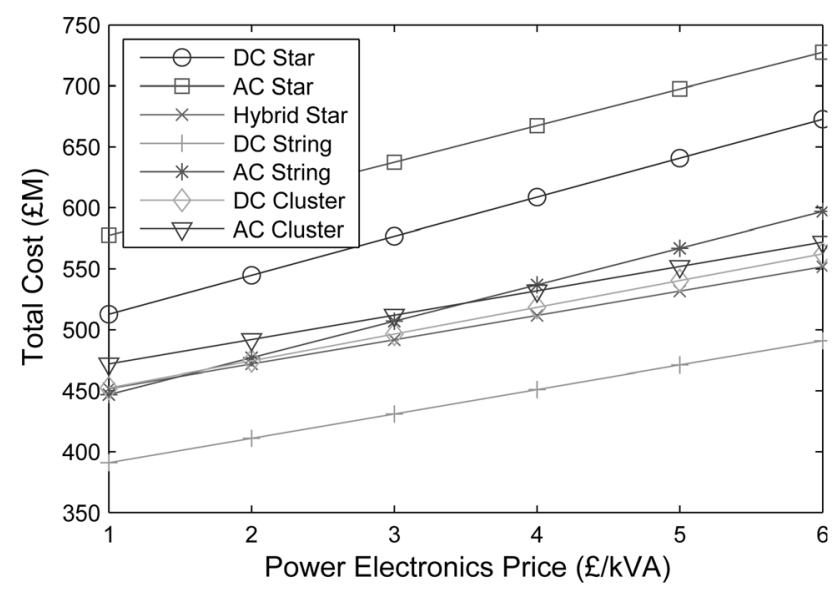

Fig. 10 Sensitivity of total cost to power electronics price

number of conversion steps, become relatively cheaper with high-power electronics prices whereas the AC string topology, having a larger number of conversion steps, is relatively cheaper with low-power electronics prices.

\section{Conclusions}

In general, the DC network topologies offer a reduction in losses, because of the reduced number of conversion steps, and costs because of the reduced cable cost. However, the lack of commercially available power electronic converters of the type required, and the lack of commercially available DC collection network cable, mean that the overall cost reduction is uncertain. With a lower power electronics price, the advantage of the DC networks is reduced.

The cluster topologies suffer from losses associated with being unable to individually control the turbine speed, but capital costs are low, similar to those of the string networks. The DC cluster topology does not offer any advantages over the AC version apart from lower cable costs, as the number of conversion steps are the same, with both networks employing a DC collection bus on the converter platform.

The AC and DC star topologies have a large number of conversion steps, leading to high costs and losses, on top of the additional losses associated with the low collection network voltage, and costs associated with the extra platforms and longer cables. A hybrid star topology was designed to reduce these disadvantages by reducing the number of conversion steps and increasing the collection network voltage. This has losses comparable with the DC string, with slightly higher costs.

If the converter is to be removed from the turbines, then the hybrid star network topology provides the lowest cost and losses, based on the assumptions used in this study. Cluster topologies are also a possible option, as the converters are located on a single platform rather than several, allowing easier access. However, fixed-speed turbines have been seen to have a higher failure rate for the gearbox and blades than variable-speed models [1], which could also be a problem in the cluster topologies, where the turbine speeds cannot individually be controlled during gusts.

Converter reliability is an important consideration, as it could be counter-productive to centralise the converters but at the same time significantly reduce the reliability, which may actually increase the downtime. In particular, failure of one of the converters for the cluster networks would lead to a whole string of turbines being unable to export power. Apart from the NPC converters used for the turbine converter in the $\mathrm{AC}$ star and string networks, most of the converters operate at a relatively high voltage, requiring the use of many series-connected switching devices. This could lead to a higher failure rate, because of the greater number of devices, especially with the DC string and star and hybrid star neworks which use a high-voltage converter for each turbine. If these converters can be designed to be tolerant of faults in individual switching devices, usually achieved through a modular design, then the converter availability can be greatly increased, and can surpass that of a much simpler converter without fault tolerance [24].

Removing the converter from the turbines can be achieved for a low cost, although this requires the use of novel power electronic converters, which are not available commercially. An alternative approach is to use fault-tolerant converters in the turbines, which has been proposed by at least one turbine manufacturer [3]. A comparison of the operations and maintenance costs, and of turbine availability, with these network topologies and with standard topologies with fault-tolerant converters would be required to determine the most cost-effective solution. This study has also used a turbine size larger than currently available, and it will be shown in another publication that smaller turbine sizes lead to significantly longer cable lengths for the star networks compared with string designs, potentially rendering them uneconomical.

\section{Acknowledgements}

This work was funded as part of the EPSRC-funded Supergen Wind Energy Technologies consortium, EP/H018662/1.

\section{References}

1 Spinato, F., Tavner, P.J., van Bussel, G.J.W., Koutoulakos, E.: 'Reliability of wind turbine sub-assemblies', IET Renew. Power Gener., 2009, 3, (4), pp. 387-401

2 van Bussel, G.J.W., Zaaijer, M.B.: 'Reliability, availability and maintenance aspects of large-scale offshore wind farms, a concepts study'. IMarEst, MAREC Conf., Newcastle Upon Tyne, March 2001

3 Zhang, T., Zain, A.: 'Modular converter system reliability and performance in design'. Second IEEE Int. Symp. on Power Electronics for Distributed Generation Systems, 2010

4 Eicher, M., Maibach, P., Faulstick, A.: 'Full size voltage converters for 5 MW offshore wind power generators'. European Wind Energy Conf., EWEC2008, 2008

5 Ng, C.H., Parker, M.A., Ran, L., Tavner, P.J., Bumby, J.R., Spooner, E.: 'A multilevel modular converter for a large, light weight wind turbine generator', IEEE Trans. Power Electron., 2008, 23, (3), pp. 1062-1074

6 Zahn, C., Smith, C., Crane, A., Bullock, A., Grieve, D.: 'DC transmission and distribution system for a large offshore wind farm'. Ninth IET Int. Conf. on AC and DC Power Transmission, London, 2010

7 Lundberg, S.: 'Performance comparison of wind park configurations', Technical Report, Chalmers University of Technology, Goteborg, Sweden, 2003

8 Prasai, A., Yim, J.-S., Divan, D., Bendre, A., Suk, S.-K.: 'A new architecture for offshore wind farms', IEEE Trans. Power Electron., 2008, 23, (3), pp. 1198-1204

9 'Dogger bank wind farm factsheet'. Forewind, Technical Report, 2012 [Online] Available at http://www.forewind.co.uk/downloads/fact-sheets .html

10 McMillan, D., Ault, G.W.: 'Techno-economic comparison of operational aspects for direct drive and gearbox-driven wind turbines', IEEE Trans. Energy Convers., 2010, 25, (1), pp. 191-198

11 Quinonez-Varela, G., Ault, G.W., Anaya-Lara, O., McDonald, J.R.: 'Electrical collector system options for large offshore wind farms', IET Renew. Power Gener., 2007, 1, (2), pp. 107-114

12 Jovcic, D., Strachan, N.: 'Offshore wind farm with centralised power conversion and DC interconnection', IET Gener. Transm. Dsitrib., 2009, 3, (6), pp. 586-595 


\section{www.ietdl.org}

13 Elliott, D.W., Finney, S.J., Booth, C.: 'Single converter interface for a cluster of wind turbines'. IET Conf. on Renewable Power Generation (RPG2011), 2011

14 de Prada-Gil, M., Gomis-Bellmunt, O., Sumper, A., Bergas-Jane, J.: 'Power generation efficiency analysis of offshore wind farms connected to a SLPC (single large power converter) operated with variable frequencies considering wake effects', Energy, 2012, 37, pp. $455-468$

15 'XLPE submarine cable systems', ABB, 2010 [Online] Available at www.abb.com/cables

16 Crine, J.-P.: 'Electrical, chemical and mechanical processes in water treeing', IEEE Trans. Dielectr. Electr. Insul., 1998, 5, (5), pp. 681-694

17 Flourentzou, N., Agelidis, V.G., Demetriades, G.D.: 'VSC-based HVDC power transmission systems: An overview', IEEE Trans. Power Electron., 2009, 24, (3), pp. 592-602

18 Parker, M.A., Anaya-Lara, O.: 'An evaluation of collection network designs which eliminate the turbine converter'. European Wind Energy Association Conf., EWEA2012
19 Li, H., Chen, Z., Polinder, H.: 'Research report on numerical evaluation of various variable speed wind generator systems'. Project UpWind, Technical Report, 2006

20 'Offshore electricity transmission: Possible options for the future', National Grid Energy Transmission PLC, Technical Report, 2011 [Online] Available at http://www.nationalgrid.com/uk/Electricity/ O_shoreTransmission/ODIS/CurrentStatement/

21 'HVDC light submarine and land power cables', ABB, 2006 [Online] Available at www.abb.com/cables

22 Polinder, H., van der Pijl, F.F.A., de Vilder, G.-J., Tavner, P.J. 'Comparison of direct-drive and geared generator concepts for wind turbines', IEEE Trans. Energy Convers., 2006, 21, (3), pp. 725-733

23 Hansen, H., Helle, L.L., Blaabjerg, E., et al.: 'Conceptural survey of generators and power electronics for wind turbines', Technical Report, Risø National Laboratory, Roskilde, Denmark, 2001

24 Hammond, P.W.: 'A new approach to enhance the power quality for medium voltage drives', IEEE Trans. Appl. Ind., 1997, 33, (1), pp. 201-208 